Medicine 1994; 73 (6): 299-305.

7. Bohm A, Banyai F, Preda Y, Zamolyi K. The treatment of septicemia in pacemaker patients. Pacing Clin Electrophysiol 1996; 19 (7): 1105-1111.

\section{Infección por Mycobacterium avium en paciente con SIDA}

\section{Sr. Director:}

El Mycobacterium avium intracelulare (MAC) es un microrganismo ubicuo de distribución geográfica universal. Se puede aislar de multiples fuentes. Su puerta de entrada es el tracto respiratorio y sobre todo gastrointestinal. La infección diseminada por MAC era un hallazgo excepcional antes de la aparición del SIDA. En pacientes con SIDA el único factor de riesgo reconocido es el grado de inmunodepresión $(1,2)$. Aunque se han descrito formas localizadas en multiples niveles del organismo, afecta sobre todo el aparato digestivo siendo rara la afectación pulmonar (3). El tratamiento recomendado esta basado en combinacíones de claritromicina y etambutol.

Con la llegada de los tratameintos antirretrovirales de alta eficacia ha disminuido claramente su incidencia al tiempo que se ha modificado su espectro clínico (4). Describimos el caso de un paciente VIH con infección por MAC localizada en pulmón y mediastino.

Varón de 32 años interno en un centro penitenciario. VIH conocido desde hace seis meses. NO ADVP. Heterosexual promiscuo. Inicio tratamiento antiretroviral tres semanas antes con D4t/ 3TC, indinavir y cotrmoxazol profilactico siendo en ese momento su carga viral 100.000 copias y sus cd4 24 celulas/microlitro. Ingresa en nuestro servicio por objetivarse en una radiografía un infiltrado intersticial bilateral y adenopatías hiliares. Refería tos con escasa espectoración desde hacía dias sín disnea, dolor torácico o hemoptisis. No presentó fiebre hasta el día anterior al ingreso siendo en ese momento la temperatura de $39^{\circ}$. Exploración: buen estado general, consciente y orientado.

Cabeza y cuello, no Muguet, no adenopatías. Torax: crepitantes en bases y auscultación cardíaca normal. Abdomen y extremidades sin hallazagos.

Exploraciones complementarias: $\mathrm{T}^{\circ} 36,5$. HB: $10,1 \mathrm{mg} / \mathrm{dl}$ Hto: 32,5. VCM 86 fl. Plaquetas 429.000/Microlitro. Leucocitos $9.230 \times 1000 /$ microlitro (7940 neutrofilos, 470 linfocitos, 540 monocitos, 160 eosinófilos). Glucosa $87 \mathrm{mg} / \mathrm{dl}$. LDH 343 UI/I. GOT 3 UI/I. GPT 33 UI/I. GGT 48 UI/I. A 187 UI/L. Bilirrubina total $0,87 \mathrm{mg} / \mathrm{dl}$. Proteínas totales $7,4 \mathrm{Gr} / \mathrm{dl}$. Albumina 2,84 $\mathrm{Gr} / \mathrm{dl}$, Creatinina $1,13 \mathrm{~m} / \mathrm{dl}$, Calcio 1,13 m/dl. Fósforo 4,3 mg/dl, úrico 6,4 mg/dl. Colesterol $143 \mathrm{mg} / 100$. Triglicéridos 148 $\mathrm{mg} / 100$. Actividad de protrornbina $71 \%$, APTT 39,9\%. Gasometria arterial basal: ph 7,47, pO2 $77 \mathrm{mmHg}, \mathrm{pCO} 22,1 \mathrm{mmHg}$, bicarbonato 15,5 Mmol/1 SAT 96,5 \%. Serología a lues, toxopasma IgG y hepatitis C negatíva. AgHbs -, AcHBc +, AcHBc + Radiografía de torax: infiltado intersticial bilateral y adenopatías hiliares. TAC toracoabdominal: bloque adenopático en localización paratraqueal derecha que se extiende hasta la altura del cayado aórtico. Adenopatías paraaórticas izquierdas y en hilio pulmonar derecho. Patrón intersticial en forma de vidrio deslustrado en disposición parcheada con afectación predominantemente de pulmóm derecho, hiado, par creast bazo, via biliar, suprsrenal y riñones normales. No adenopatías intraabdominales. 3AAR de esputo seriados. Broncoscopia: aspecto macroscópico normal. Cultivo del lavado broncoalveolar negativo para bacterias, micobacterias y hongos. Tinción para Pneumocistis carinii, citología para celulas malignas. Biopsia transbronquial: moderada fibrosis septal. Punción transcarial: inflamación granulomatosa. Medias- tinoscopia con biopsia ganglionar: adenitis granulomatosa caseificante. En la muestra de ganglio mediastínico se informa crecimiento de MAC instaurándose en ese momento tratamiento con claritromicina y etambutol.

Tras la introducción del tratamiento antiretroviral de alta eficacia en el manejo del SIDA, la infección por MAC ha visto modificado su espectro clínico en pacientes VIH. Se han descrito cuadros de linfadenitis focales (cervicales, torácicas o abdominales), fiebre elevada y leucocitosis en las primeras semanas tras la introducción del tratamiento antiretroviral. Estos cuadro serían consecuencia de la recuperación de la capacidad de respuesta imflamatoria ante una infección preexistente pero subclínica por MAC en individuos muy deteriorados inmunológicamente (4).

En resumen, tras la introducción del tratamiento antiretroviral de alta eficacia, ha cambiado la frecuencia y forma de presentación de las complicaciones infecciosas o no de la infección por VIH. Así ante un paciente VIH con sintomatología pulmonar, patrón intersticial y adenopatias hiliares que ha comenzado recientemente con tratamiento antiretroviral, deberíamos descartar la infección por MAC.

\section{J. Sánchez Ayuso, S. Mateo Álvarez}

Servicio de Medicina Interna. Unidad de Acceso Restringido. Hospital 12 de Octubre. Madrid

1. Nlghtingale SD, et al. Incidence of Mycobacterium avium-intracellulare complex bacteriemia in human immunodeficency virus-positive patients. J Infect Dis 1992; 165: 1082-1088.

2. Jacobson MA, et al. Natural History of diseminated Mycobacterium avium complex infections in AIDS. J Infect Dis 1991; 164: 994-998.

3. Gordin FM, et al. Early manifestation of disseminated Mycobacterium avium complex disease: A prospective evaluation. J Infect Dis 1997; 176: 126-132.

4. Race EM, et al. Focal mycobacterial lymphadenitisfollowing initiation of protease inhibitor therapy in patients with advanced HIV disease. Lancet 1998; 351: 252-255.

Hemoptisis amenazante en el aneurisma de aorta. A propósito de un caso con supervivencia prolongada

\section{Sr. Director:}

La hemoptisis amenazante representa menos del 5\% de todos los casos de hemoptisis. Sin embargo, por su alta mortalidad obliga a adoptar medidas diagnósticas (broncoscopia) y terapéuticas urgentes (embolización de las arterias bronquiales o resección quirúrgica), con el fin de controlar el sangrado activo. Las causas más frecuentes son la tuberculosis, las bronquiectasias y el cáncer de pulmón (1). El aneurisma de aorta es una causa poco común de hemoptisis amenazante, que se acompaña de una elevada mortalidad cuando no se diagnostica e indica un tratamiento quirúrgico precoz, siguiendo un protocolo de actuación diferente a otros pacientes con hemoptisis amenazante (2).

Debido a su rareza y a la supervivencia excepcionalmente prolongada, presentamos el caso de un anciano con hemoptisis amenazante por un aneurisma de aorta que sigue vivo después de 18 meses, junto a una revisión de la literatura.

Se trata de un varón de 76 años que ingresa en nuestro servicio en noviembre de 1999, por hemoptisis amenazante $(>200 \mathrm{ml}$ en menos de 12 horas). Entre los antecedentes destacaban hiperten- 


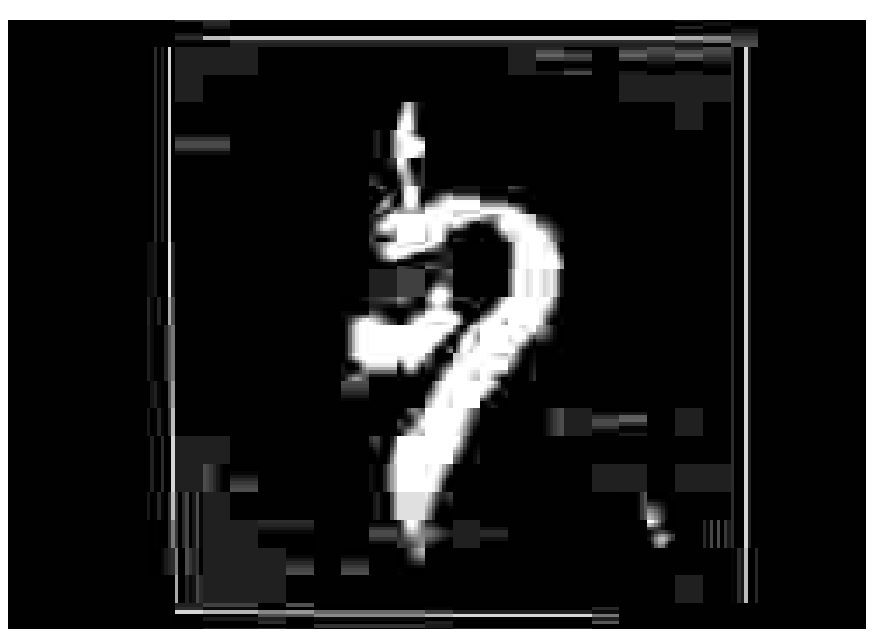

Fig. 1. Resonancia magnética vascular de tórax y abdomen. Nótese la existencia de un aneurisma de aorta que se extiende desde la salida de la arteria subclavia izquierda hasta la bifurcación aórtica.

sión arterial en tratamiento (nifedipino y enalapril) y hemoptisis masiva en mayo de 1998 relacionada con un aneurisma de aorta. Entonces, la broncoscopia mostró restos hemáticos difusos, estenosis del BLII por un coágulo y signos de compresión extrínseca en la traquea, mientras que en la $T C$ se evidenció un aneurisma de aorta con trombosis mural y un infiltrado alveolar en LII, sugestivo de hemorragia a dicho nivel. Debido a la extensión del aneurisma se desestimó la opción quirúrgica. El paciente mejoró con tratamiento conservador.

La radiografía de tórax pone de manifiesto una dilatación de la aorta torácica. El electrocardiograma es normal. En los análi sis de sangre y orina destaca hematocrito $34 \%$, el resto de determinaciones con autoanticuerpos y complemento son normales. En el esputo: Ziehl-Löwenstein y citologías negativos. IRM vas cular: aorta torácica descendente aneurismática y parcialmente trombosada (78 $\mathrm{mm}$ de diámetro máximo), que se extiende desde la salida de la arteria subclavia izquierda hasta la bifurcación aórtica (Fig. 1).

Con tratamiento conservador (reposo, control de la presión arterial, codeina y ácido aminocaproico) desaparece la hemoptisis y se procede al alta hospitalaria doce días después.

El aneurisma de aorta es una rara causa de hemoptisis amenazante que habitualmente, en ausencia de un tratamiento quirúrgico precoz, tiene un pronóstico fatal a corto plazo, como consecuencia de una fístula aortobronquial que en el $90 \%$ de los casos drena en el árbol bronquial izquierdo y ocasiona la muerte por asfixia. En este sentido, Pérez del Llano, y cols. (3) comunican el caso de un varón de 74 años con hemoptisis recurrente de 20 días de evolución, que falleció 17 días después por hemoptisis masiva, en el que como en el paciente actual, se había rechazado el tratamiento quirúrgico. Por el contrario, Julia Serda, y cols. (4) presentan tres casos de fístulas aortobronquiales que se manifestaron como hemoptisis masiva y fueron tratados quirúrgicamente. Ferretti, y cols. (5) han comunicado recientemente el caso de un varón de 82 años con hemoptisis recidivante de 12 meses de evolución por una fístula aortobronquial, aunque a diferencia del paciente actual, había sido intervenido por traumatismo de aorta varios años antes. De hecho, se ha señalado que aunque el $87 \%$ de las fístulas aortobronquiales se deben a aneurismas, el $75 \%$ de los casos son secundarios a reparaciones de anomalías congénitas, como la coartación aórtica (2).

Aunque las exploraciones radiológicas no invasoras (TC, IRM) pueden sugerir la existencia de una fístula aortobronquial, la aortografía es la exploración de referencia. Sin embargo, a menudo es difícil documentarla porque sólo excepcionalmente se observa en las primeras y, cuando está obstruida por coágulos de sangre, no es evidente en la segunda. En este sentido, la TC puede mostrar la relación del aneurisma con las estructuras adyacentes así como una consolidación pulmonar contigüa a la aorta o la presencia de coágulos de sangre dentro del árbol bronquial. La demostración de un tracto continuo entre la aorta y el árbol bronquial sólo ha sido documentada recientemente por Elmadbouh, y cols. (6) en una fístula aortotraqueal postquirúrgica. En la broncoscopia, el orificio de la fístula apareció como una alteración inespecífica de la mucosa traqueal.

Aparte de la fístula aortobronquial, otro mecanismo de hemoptisis es la compresión del pulmón por el aneurisma, que puede provocar una erosión de pequeños vasos o un colapso bronquial con infección posterior del parénquima pulmonar subyacente (3).

En definitiva, a pesar de no realizar una aortografía, la hemoptisis masiva y consolidación pulmonar basal izquierda junto a los datos de broncoscopia y TC permiten sospechar, según nuestra opinión, la existencia de una fístula aortobronquial en el caso actual, lo que hace excepcional la supervivencia documentada, probablemente por la obstrucción intermitente de dicha fístula por coágulos.

\section{F. Carrión Valero, E. Mª Rodríguez Castro, J. Marín Pardo}

Servicio de Neumología. Hospital Clínico Universitario de Valencia. Universitat de València.

1. Rudzinski JP, del Castillo J. Massive hemoptysis. Ann Emerg Med 1987; 16: 561-564

2. Martín Zapatero E, Martí Beltrán S, Domínguez R. Hemoptisis por fístula aorto-bronquial. Med Clin (Barc) 1996; 106: 318-319.

3. Pérez Llano LA, Soilán JL, Armesto V. Hemoptisis recurrente como forma de presentación de un aneurisma sacular de la aorta torácica. Presentación de un caso. Arch Bronconeumol 1997; 33: 364-365.

4. Julia Serda G, Freixinet J, Abad C, Rodríguez de Castro F, López L, Caminero J, et al. Massive hemoptysis as a manifestation of fistulized thoracic aortic aneurysm into the bronchial tree. J Cardiovas Surg Torino 1996; 37: 417-419.

5. Ferretti GR, Choplin RH, Haponik EF, Hudspeth AS. Aortic pseudoaneurysm with aortobronchial fistula: diagnosis with CT angiography. J Comput Assist Tomogr 1996; 20: 975-978.

6. Elmadbouh HM, Ruttley MST, Bushan K, Musumeci F. Aortotracheal fistula: demonstration by computerized tomography. Thorac Cardiovas Surg 1997; 45: 142-144.

\section{Diagnóstico simultáneo de leucemia linfocítica crónica y policitemia vera en un paciente}

\section{Sr. Director:}

La coexistencia en un mismo paciente de una enfermedad linfoproliferativa y otra mieloproliferativa, es un hecho raro y pocas veces recogido en la literatura (1). La leucemia linfocítica crónica (LLC) se asocia con relativa frecuencia a tumores sólidos, pero raramente coincide con otras neoplasias hematológicas. Concretamente, resulta ciertamente inusual el diagnóstico simultáneo de policitemia vera (PV) y LLC en un mismo paciente (2-4), habiéndose descrito así mismo de forma excepcional la aparición de LLC en el curso de una PV.

Describimos el caso de un varón de 84 años, con antecedentes de hipertensión arterial esencial e intervenciones quirúrgicas 